\title{
Relation Between Perceived Health and Sick Leave in Employees With a Chronic Illness
}

\author{
Cécile R. L. Boot • Lando L. J. Koppes • \\ Seth N. J. van den Bossche • Johannes R. Anema • \\ Allard J. van der Beek
}

Published online: 14 December 2010

(C) The Author(s) 2010. This article is published with open access at Springerlink.com

\begin{abstract}
Introduction: To improve work participation in individuals with a chronic illness, insight into the role of work-related factors in the association between health and sick leave is needed. The aim of this study was to gain insight into the contribution of work limitations, work characteristics, and work adjustments to the association between health and sick leave in employees with a chronic illness. Methods: All employees with a chronic illness, between 15 and 65 years of age $(n=7,748)$ were selected from The Netherlands Working Conditions Survey. The survey included questions about perceived health, working conditions, and sick leave. Block-wise multivariate linear regression analyses were performed and, in different blocks, limitations at work, work characteristics, and work adjustments were added to the model of perceived health status. Changes in regression coefficient (B) (\%) were calculated for the total group and for sub-groups per
\end{abstract}

C. R. L. Boot $(\varangle)$. J. R. Anema · A. J. van der Beek Department of Public and Occupational Health, EMGO Institute for Health and Care Research, VU University Medical Center, Room BS7-C573, P.O. Box 7057, 1007 MB Amsterdam,

The Netherlands

e-mail: crl.boot@vumc.nl

C. R. L. Boot - L. L. J. Koppes - S. N. J. van den Bossche ·

J. R. Anema - A. J. van der Beek

Body@Work, Research Center on Physical Activity, Work and Health, TNO-VU University Medical Center,

Amsterdam, The Netherlands

L. L. J. Koppes · S. N. J. van den Bossche

TNO Quality of Life, Division Work and Employment,

Hoofddorp, The Netherlands

J. R. Anema - A. J. van der Beek

Research Center for Insurance Medicine AMC-UMCG-UWV-

VUmc, Amsterdam, The Netherlands chronic illness. Results: When work limitations were added to the model, the $\mathrm{B}$ between health and sick leave decreased by $18 \%$ ( 5.0 to 4.1 ). Adding work characteristics did not decrease the association between health and sick leave, but the B between work limitations and sick leave decreased by $14 \%$, (5.3 to 4.5$)$. When work adjustments were added to the model, the Bs between sick leave and work limitations and work characteristics changed from 4.5 to 3.4 for work limitations and from 2.1 to 1.9 for temporary contract and from -0.8 to -1.0 for supervisor support. Conclusions: The association between health and sick leave was explained by limitations at work, work characteristics, and work adjustments. Paying more attention to work limitations, characteristics and adjustments offers opportunities to reduce the negative consequences of chronic illness.

Keywords Chronic disease - Work - Sick leave . Health $\cdot$ Confounding factors

\section{Introduction}

Participation in society is described by the WHO as the ultimate goal for every individual [1], and important domain of societal participation is participation in paid work. In the ageing society, the prevalence of chronic illnesses will increase [2-4], and the concurrent rise in the age of retirement will result in an increasing number of chronically ill individuals in the working population [5]. It is known that sick leave in employees with a chronic illness is higher than in employees with no chronic illness [6]. In addition, employees with a chronic illness more often have long-term work-disablement, compared to the general population $[7,8]$. 
Previous research has shown that psychosocial and work-related variables are strong predictors for employment status in a population with low back pain [9]. In studies focussing on employees with asthma and COPD, airway obstruction was not the main determinant of sick leave; it was found that job control opportunities and psychological variables were associated with sick leave [10]. In a study population of employees with depressive disorders, work disability was found to be predicted by worse social and occupational functioning and a longer duration of depression [11].

These are only a few of the many studies focussing on sick leave and work disability in employees with a specific chronic disorder. Illness perceptions have been found to be associated with occupational status in chronically ill patients [12], but the results of these studies are difficult to compare, since different populations (different chronic illnesses), different outcome measures, and different sets of factors were investigated. Research on populations with different chronic illnesses is scarce. A study focussing on patients with a variety of chronic illnesses revealed that decreased participation in the labour market was associated with health problems that can be considered as common consequences of a chronic illness [13]. Sick leave is known to be a multifactorial outcome, but the nature of the chronic illness only explains (a small) part of the sick leave.

From the above it can be concluded that both healthrelated and work-related factors are associated with participation in paid work. However, it remains unclear whether a lower health status, due to a chronic illness, has a direct effect on participation in paid work, or sick leave, or that unfavourable work characteristics cause a deterioration in health status, resulting in an overestimation of the contribution of low health status on sick leave. It has been demonstrated that certain work characteristics may negatively influence health status [14-16]. Consequently, the association between health and sick leave may be an overestimation of the true association when unfavourable work characteristics have a negative effect on health status. Likewise, perceived limitations at work and the nonrealization of work adjustments may be associated with a lower health status, therewith increasing the association between health status and sick leave. Insight into these inter-relationships will be valuable when setting priorities for interventions.

Sick leave is known to be an early indicator of future health problems and mortality [17]. We hypothesize that perceived limitations at work are a first signal of unfavourable work characteristics, and that the association between health and sick leave will decrease when work limitations are added to the model. In line with this, some work characteristics may not (yet) lead to work limitations, but may contribute to the explanation of sick leave. A second hypothesis is that adding work characteristics to the model for sick leave containing health and work limitations may decrease not only the association between health and sick leave, but also the association between work limitations and sick leave, and that the opposite will apply to favourable work characteristics. Our third hypothesis is that work adjustments that have been realized decrease the association between health and sick leave, and also the association between work characteristics and sick leave.

The main aim of this study was to gain insight into the contribution of work limitations, work characteristics, and work adjustments to the association between health and sick leave in employees with a chronic illness. A secondary aim was to gain insight into differences and similarities between various chronic illnesses with regard to the contribution of work limitations, work characteristics, and work adjustments to the association between health and sick leave.

\section{Methods}

\section{Sample}

Data were obtained from The Netherlands Working Conditions Survey (NWCS), which is a large scale periodical investigation into the working conditions of employees in The Netherlands, for which random sampling from the 'jobs register' was carried out by Statistics Netherlands [18]. This database contains information on all jobs falling under the Dutch Employee Benefit schemes that are liable to income tax. The NWCS focuses on employees aged between 15 and 65 years of age. Self-employed individuals are excluded from the sampling framework.

The responses are weighed for gender, age, professional group, ethnic origin, level of urbanization, geographical region, and level of education, to obtain a representative sample of the distribution of these factors in all employees in The Netherlands. In all cases, weight coefficients and standard deviations fall within acceptable limits.

A total of 22,759 employees completed the NWCS questionnaire in November/December 2007 (response rate: $33 \%$ ). Only the 7,748 (34\%) participants who reported at least one chronic illness were selected for analysis in the present study.

\section{Questionnaire}

Data were collected by means of Paper and Pencil Interviewing and Computer Assisted Web Interviewing. The participants were free to choose whether they completed the paper and pencil questionnaire (which was sent to them by post), or accessed the questionnaire on the internet by means of a personal code. Pilot studies were conducted 
before the start of the actual study to evaluate the length and clarity of the questionnaire. The average time needed to complete the questionnaire was approximately $25 \mathrm{~min}$.

\section{Demographics}

Data on age (year of birth), gender (male/female), and level of education (8 categories, ranging from no to academic degree) were collected in the questionnaire. Level of education was dichotomised into high (higher vocational education or academic degree) and low level of education (including intermediate and primary education).

\section{Chronic Illness}

The presence of a chronic illness was assessed with one question: 'Do you have one or more of the following chronic diseases, disorders or handicaps, and if so, could you please indicate which one?' (more than one answer allowed). Answering categories were: none; problems with arms or hands (including arthritis, rheumatoid disorders and complaints of the arm, neck and/or shoulder [CANS]); problems with legs or feet (including arthritis and rheumatoid disorders); problems with back or neck (including arthritis, rheumatoid disorders and CANS); migraine or severe headache; cardiovascular disease; asthma, bronchitis, or emphysema; stomach or bowel disorders; diabetes; severe skin disorders; mental disorders; hearing problems; epilepsy; life-threatening illness (e.g. cancer, AIDS); vision problems; other chronic disorders or illnesses.

\section{Perceived Health}

Perceived health was assessed with a single question: 'how do you evaluate your health in general?', with a score ranging from 1 (excellent) to 5 (bad) [19].

\section{Limitations at Work}

Limitations at work were assessed with the following question: 'Do you experience limitations at work because of your illness, disorder or handicap?' with answering categories of (1) not at all, (2) slight limitations, and (3) severe limitations. This was dichotomised into no limitations (1), and limitations (2 and 3).

\section{Work Characteristics}

A broad range of work characteristics was investigated. These included: type of contract (permanent or temporary); working hours (full time or part time); shift work (often/sometimes vs. never); working evenings or nights (often/sometimes vs. never); working during the weekend (often/sometimes vs. never); working overtime (often/ sometimes vs. never); management job (yes vs. no); dangerous work (often/sometimes vs. never); physical strain (often/sometimes vs. never); exposure to vibrations (often/ sometimes vs. never); uncomfortable work posture (often/ sometimes vs. never); repetitive movements (often/sometimes vs. never); exposure to chemicals (often/sometimes vs. never); exposure to work-related noise (often/sometimes vs. never), and exposure to work-home interference (often vs. sometimes/never), and exposure to home-work interference (often/sometimes vs. never). These characteristics were all dichotomised with cut-off points based on logical reasoning and power per category $(\geq 20 \%$ in the smallest category).

Company size was reduced to five categories $(<10$; $10-49 ; 50-99 ; 100-499 ; \geq 500$ employees), with scale variables of contractual working hours per week, duration of employment at present employer (years), and duration of employment with current job (years).

A number of other scales were also used: job autonomy (average score of 5 items, range 1-3); working under timepressure (average score of 2 items, range 1-3); high task requirements (average score of 4 items, range 1-4); emotional work-load (average score of 3 items, range 1-4); difficult job (average score of 3 items, range 1-4); innovative atmosphere at work (average score of 4 items, range $1-4)$; job variety (average score of 3 items, range 1-4); social support from supervisor (average score of 4 items, range 1-4); and social support from colleagues (average score of 4 items; range 1-4).

\section{Work Adjustments}

Work adjustments were investigated with the following question: 'Over the past 12 months, have any adjustments been made in your work or working environment because of your health condition?' with answering options: no adjustments; adjustments in devices or furniture; adjustments in working hours; adjustments in the amount of work; change of job or job tasks; education or retraining; adjustments in access to the office; adjustments in work environment or job content; and other adjustments. These answers were modified into: any work adjustments realised in the past 12 months because of a health condition (yes/no).

\section{Sick Leave}

Sick leave was investigated by asking about the number of work days on sick leave during the past 12 months, and also the number of work days per week. The sickness 
absence percentage was then calculated per person by dividing the number of work days on sick leave by the number of work days per year.

\section{Analyses}

All analyses were performed twice. First, all employees with a chronic illness were analysed as one group, and then the same analysis was performed separately for all chronic illness groups containing at least 500 cases. This cut-off point was chosen based on the total number of variables and the assumption that at least 10 cases are needed for each independent variable (continuous or dichotomous). Sick leave (i.e. sickness absence percentage) was the dependent variable in all analyses. Perceived health, work limitations, work characteristics, and work adjustments were the independent variables.

Block-wise linear regression analyses were performed with the Enter method. The first block contained perceived health with gender, age and level of education as confounders; the second block contained the limitations at work, the third block contained all work characteristics, and the fourth block consisted of the work adjustment variable.

In block 1 , the association between health and sick leave was examined (B 1). In block 2, the association between health and sick leave was examined again (B 2), and the difference between B 2 and B 1 for health was calculated ( $\Delta$ B 2-1). By adding blocks 3 and 4, the Bs were calculated in a similar way, thus leading to B 3, B 4, $\Delta$ B 3-2 and $\Delta$ B 4-3 for the health variables.

A change in B was considered to be relevant if the B had a $P$ value lower than 0.05 and the change in $\mathrm{B}$ was at least $10 \%$. All analyses were performed in SPSS version 15.0 for Windows.

\section{Results}

\section{Study Sample}

The sample consisted of 7,748 employees with a chronic illness (average age 43 years, 49\% female). Disorders of the neck or back had the highest prevalence (28\%), followed by migraine and severe headache $(16 \%)$, problems with arms and hands (15\%), and asthma/COPD (15\%). Sixty-one percent reported at least one episode of sick leave in the past 12 months, and the average number of episodes was 1.6. The mean sick leave was $7.5 \%$. The sample characteristics are summarized in Table 1 , and the results of the descriptive analyses of the factors associated with sick leave are presented in Table 2.
Multivariate Analyses of the Total Group With a Chronic Illness

In the total group of employees with a chronic illness, a lower perceived health status was significantly associated with more sick leave (B: 5.0) (Table 3, model 1). This association remained significant and in the same direction after adding limitations at work (B: 4.1), work characteristics (B: 3.7) and work adjustments (B: 3.5) to the model.

The association between perceived health and sick leave decreased by $17.8 \%$ (5.0 to $>4.1$ ), after adding limitations at work to the model (Table 3, model 2, delta block 2-1). More sick leave was associated with a permanent contract (compared to a temporary contract), never working in evenings or nights, never working overtime, less autonomy, a higher emotional work-load, less social support from the supervisor, and more interference of home in the work situation (Table 3, model 3). Adding the work characteristics to the multivariate model resulted in no relevant change ( $\mathrm{B}$ change $<10 \%$ ) in the association between perceived health and sick leave, but the association between limitations at work and sick leave decreased by $14.3 \%$ (Table 3, delta block 3-2).

Realised work adjustments was significantly associated with more sick leave (B: 6.5) (Table 3, model 4). Adding work adjustments to the model resulted in no relevant change ( $\mathrm{B}$ change $<10 \%$ ) in the association between perceived health and sick leave, but the association between work limitations and sick leave decreased by $25.9 \%$. In addition, the association between type of contract and sick leave decreased by $11.6 \%$, the association between not working in the evening and sick leave decreased by $10.6 \%$, and the association between less social support from the supervisor and sick leave increased by $23.5 \%$ (Table 3, delta block 4-3).

\section{Illness-Specific Associations Between Health Status} and Sick Leave

\section{Perceived Health Status}

A lower perceived health status was significantly associated with more sick leave in each chronic illness group (B $>0 ; P<0.05$ ) (Table 4). Adding work limitations to the multivariate model decreased the associations between perceived health and sick leave for all groups with a specific chronic illness, but the change was not considered to be relevant for the groups with migraine/headache $(-6.6 \%)$ and problems with arms or hands $(-8.8 \%)$.

Adding work characteristics to the multivariate model resulted in a relevant decrease in the association between perceived health and sick leave in the groups with 
Table 1 Sample characteristics

\begin{tabular}{|c|c|c|c|}
\hline Variable & Categories & & \\
\hline \multirow[t]{2}{*}{ Gender } & Male & $\mathrm{n}(\%)$ & $3,968(51)$ \\
\hline & Female & & $3,780(49)$ \\
\hline Age & Years & Mean (SD) & $43(12)$ \\
\hline \multirow[t]{2}{*}{ Level of education } & Low/middle & $\mathrm{n}(\%)$ & $5,618(73)$ \\
\hline & High & & $2,092(27)$ \\
\hline \multirow[t]{15}{*}{ Chronic illness } & $\begin{array}{l}\text { Problems with back or neck (including arthritis, rheumatoid } \\
\text { disorders and CANS) }\end{array}$ & $\mathrm{n}(\%)$ & $2,166(28)$ \\
\hline & Migraine or severe headache & & $1,212(16)$ \\
\hline & $\begin{array}{l}\text { Problems with arms or hands (including arthritis, rheumatoid } \\
\text { disorders and CANS) }\end{array}$ & & $1,198(15)$ \\
\hline & Asthma, bronchitis, emphysema & & $1,147(15)$ \\
\hline & $\begin{array}{l}\text { Problems with legs or feet (including arthritis and rheumatoid } \\
\text { disorders) }\end{array}$ & & $952(12)$ \\
\hline & Stomach or bowel disorders & & $754(10)$ \\
\hline & Cardiovascular illness & & $553(7)$ \\
\hline & Mental disorders & & $532(7)$ \\
\hline & Hearing problems & & $484(6)$ \\
\hline & Vision problems & & $455(6)$ \\
\hline & Diabetes & & $450(6)$ \\
\hline & Severe skin disorders & & $180(2)$ \\
\hline & Life threatening illness (e.g., cancer, AIDS) & & $159(2)$ \\
\hline & Epilepsy & & $82(1)$ \\
\hline & Other chronic illness & & $1,219(16)$ \\
\hline \multirow[t]{3}{*}{ Sick leave } & Any sick leave in last 12 months & $\mathrm{n}(\%)$ & $4,723(61)$ \\
\hline & Sick leave frequency in last 12 months & Mean (SD) & $1.62(3.51)$ \\
\hline & Sick leave percentage in last 12 months & Mean (SD) & $7.51(17.75)$ \\
\hline
\end{tabular}

$(\mathrm{N}=7,748)$, CANS complaints of the arms neck or shoulder

problems with back or neck, migraine or severe headache, asthma, bronchitis or emphysema, stomach or bowel disorders, and mental disorders. Realised work adjustments only resulted in a relevant decrease in the association between health and sick leave in the group with complaints of legs/feet.

\section{Work Limitations}

Experiencing more limitations at work because of a chronic illness was significantly associated with more sick leave in all chronic illness groups. Adding work characteristics to the model decreased this association within the groups with problems with back or neck, asthma, bronchitis or emphysema, problems with legs or feet, stomach or bowel disorders, cardiovascular disease, and mental disorders. When work adjustments were added to the multivariate model, the association between work limitations and sick leave was further decreased in the groups with complaints of the back or neck and mental disorders.

\section{Discussion}

The main finding in this exploratory study was that in a population of employees with chronic illnesses, limitations at work, work characteristics, and work adjustments partially explain the association between perceived health and sick leave. These findings support the hypothesis that intervening on work-related factors might reduce the association of poor perceived health status with sick leave in employees with a chronic illness. However, the direction of this effect needs to be confirmed with longitudinal data.

\section{Factors Associated With Sick Leave in Employees} With a Chronic Illness

No major differences were observed in the association between perceived health and sick leave in employees with different chronic illnesses. In general, a lower perceived health status was associated with a higher rate of sick leave (a higher number of sickness absence days). Taking 
Table 2 Descriptive data of determinants of sick leave percentage

\begin{tabular}{|c|c|c|c|}
\hline Block & Determinants & Range/categories & Mean (SD)/n (\%) \\
\hline Block 1 & Perceived health status & 1 (excellent) to 5 (bad) & $2.9(0.8)$ \\
\hline Block 2 & Limitations at work & Light/severe vs. none & Light/severe: 3,914 (51\%) \\
\hline \multirow[t]{32}{*}{ Block 3} & Type of contract & Temporary vs. permanent & Temporary: 1,077 (14\%) \\
\hline & Working hours & $>32$ vs. $\leq 32 \mathrm{~h}$ per week & $>32$ h/week: 4,289 (56\%) \\
\hline & Shift work & Often/sometimes vs. never & Often/sometimes: 1,049 (14\%) \\
\hline & Working at evening or night & Often/sometimes vs. never & Often/sometimes: $3,512(49 \%)$ \\
\hline & Working in weekends & Often/sometimes vs. never & Often/sometimes: $3,708(51 \%)$ \\
\hline & Working overtime & Often/sometimes vs. never & Often/sometimes: $5,453(71 \%)$ \\
\hline & Time span at current employer & years & $11.7(10.5)$ \\
\hline & Time span in current job & years & $8.5(8.9)$ \\
\hline & Company size & $<10$ employees & $<10: 1,064(14 \%)$ \\
\hline & & 10-49 employees & 10-49: 2,054 (27\%) \\
\hline & & 50-99 employees & 50-99: 1,176 (16\%) \\
\hline & & 100-499 employees & 100-499: $1,751(23 \%)$ \\
\hline & & $\geq 500$ employees & $\geq 500: 1,536(20 \%)$ \\
\hline & Management job & Yes vs. no & Yes: 2,060 (27\%) \\
\hline & Dangerous work & Often/sometimes vs. never & Often/sometimes: $1,750(23 \%)$ \\
\hline & Physical strain in work & Often/sometimes vs. never & Often/sometimes: $3,220(42 \%)$ \\
\hline & Exposure to vibrations & Often/sometimes vs. never & Often/sometimes: 1,461 (20\%) \\
\hline & Uncomfortable posture & Often/sometimes vs. never & Often/sometimes: $3,116(42 \%)$ \\
\hline & Repetitive movements & Often/sometimes vs. never & Often/sometimes: 4,749 (64\%) \\
\hline & Exposure to chemicals & Often/sometimes vs. never & Often/sometimes: 2,252 (29\%) \\
\hline & Exposure to noise & Often/sometimes vs. never & Often/sometimes: 2,218 (29\%) \\
\hline & Autonomy & 1 (no) to 3 (often) & $2.5(0.5)$ \\
\hline & Time pressure & 1 (no) to 3 (often) & $2.2(0.7)$ \\
\hline & High task requirements & 1 (no) to 4 (always) & $2.4(0.6)$ \\
\hline & Emotional load & 1 (no) to 4 (always) & $1.8(0.6)$ \\
\hline & Job difficulty & 1 (no) to 4 (always) & $3.1(0.7)$ \\
\hline & Innovative power & 1 (no) to 4 (always) & $2.2(0.7)$ \\
\hline & Job variety & 1 (no) to 4 (always) & $2.7(0.7)$ \\
\hline & Social support by supervisor & 1 (little) to 4 (much) & $2.8(0.7)$ \\
\hline & Social support by colleagues & 1 (little) to 4 (much) & $3.2(0.5)$ \\
\hline & Interference of work at home & Often vs. sometimes/never & Often: $916(12 \%)$ \\
\hline & Interference of home at work & Often/sometimes vs. never & Often/sometimes: 2,265 (30\%) \\
\hline Block 4 & Work adjustments realised & Yes vs. no & Yes: 1,674 (22\%) \\
\hline
\end{tabular}

limitations at work into consideration decreased the strength of the association between sick leave and perceived health status by more than $15 \%$. This implies that perceived health status and limitations at work explain a similar part of the variance in sick leave. It is hypothesized that the negative association of health status with sick leave is partially caused by the work limitations experienced by employees. Furthermore, reducing work limitations could therefore decrease the impact of low perceived health status on sick leave. Data from longitudinal studies are needed to confirm these hypotheses.

Similar patterns were observed for work characteristics and work adjustments. The reduction in the association between perceived health status and sick leave when work characteristics were added to the model can be explained by the fact that work characteristics and perceived health status explain similar part of the variance in sick leave. The hypothesis, based on the results of this study, is that favourable work characteristics, or realized work adjustments may decrease the impact of a low perceived health status on sick leave. This is in line with the existing evidence of the positive effects of work adjustments on return to work in employees who are on sick leave [20-22].

One remarkable finding needs to be discussed. Work adjustments were associated with more sick leave. Since it 
Table 3 Multivariate model of the associations (Bs) of the determinants of sick leave (independent variables) with sick leave (\%, dependent variable) in employees with a chronic illness

\begin{tabular}{|c|c|c|c|c|c|c|c|c|}
\hline \multirow[t]{2}{*}{ Blocks } & \multirow[t]{2}{*}{ Determinants } & \multicolumn{4}{|l|}{ B } & \multicolumn{3}{|c|}{ Delta B (\%) } \\
\hline & & Model 1 & Model 2 & Model 3 & Model 4 & Model 2-1 & Model 3-2 & Model 4-3 \\
\hline 1. Perceived health & Lower health status & 5.0 & 4.1 & 3.7 & 3.5 & -17.8 & -9.3 & -6.7 \\
\hline 2. Limitations at work & More limitations at work & & 5.3 & 4.5 & 3.4 & & -14.3 & -25.9 \\
\hline \multirow[t]{7}{*}{ 3. Work characteristics ${ }^{a}$} & Temporary contract & & & -2.1 & -1.9 & & & -11.6 \\
\hline & Working in evening or night & & & -1.4 & -1.3 & & & -10.6 \\
\hline & Working overtime & & & -3.4 & -3.3 & & & -3.8 \\
\hline & More autonomy & & & -1.7 & -1.8 & & & 1.5 \\
\hline & Higher emotional load & & & 1.1 & 1.0 & & & -8.1 \\
\hline & More supervisor support & & & -0.8 & -1.0 & & & 23.5 \\
\hline & $\begin{array}{l}\text { Interference of home } \\
\text { in work situation }\end{array}$ & & & 1.3 & 1.3 & & & -1.4 \\
\hline 4. Work adjustments & Work adjustments realised & & & & 6.5 & & & \\
\hline
\end{tabular}

${ }^{a}$ Only work characteristics with significant Bs are shown. Relevant changes in B (>10\%) are in bold type

Table 4 Multivariate model of the association (B) of determinants of perceived health status and limitations at work (independent variables) with sick leave (\%, dependent variable) in employees with various chronic illnesses

\begin{tabular}{|c|c|c|c|c|c|c|c|}
\hline \multirow[t]{2}{*}{ Determinants of sick leave } & \multicolumn{4}{|c|}{ B per model } & \multicolumn{3}{|c|}{ Delta B $(\%)^{\mathrm{a}}$} \\
\hline & 1 & 2 & 3 & 4 & $2-1$ & $3-2$ & $4-3$ \\
\hline \multicolumn{8}{|l|}{ Lower perceived health status } \\
\hline Complaints of back or neck & 5.0 & 4.0 & 3.4 & 3.1 & -19.4 & -14.1 & -8.3 \\
\hline Migraine or severe headache & 4.1 & 3.8 & 3.4 & 3.1 & -6.6 & -10.2 & -9.2 \\
\hline Complaints arms or hands & 6.4 & 5.9 & 5.5 & 5.0 & -8.8 & -7.0 & -8.9 \\
\hline Asthma, bronchitis or emphysema & 3.7 & 3.0 & 2.7 & 2.4 & -17.9 & -12.6 & -8.9 \\
\hline Problems with leg or feet & 4.5 & 3.5 & 3.2 & 2.5 & -21.7 & -9.4 & -23.5 \\
\hline Stomach or bowel disorders & 4.3 & 3.5 & 3.0 & 2.9 & -19.6 & -12.6 & -5.6 \\
\hline Cardiovascular disease & 8.6 & 6.1 & 6.2 & 6.1 & -29.6 & 3.1 & -1.8 \\
\hline Mental disorders & 7.8 & 5.4 & 4.9 & 4.9 & -29.8 & -10.0 & 0.9 \\
\hline \multicolumn{8}{|l|}{ More limitations at work } \\
\hline Complaints of back or neck & & 5.4 & 4.5 & 3.5 & & -16.0 & -21.4 \\
\hline Migraine or severe headache & & 2.1 & NS & NS & & $\mathrm{NC}$ & $\mathrm{NC}$ \\
\hline Complaints arms or hands & & 4.0 & NS & NS & & $\mathrm{NC}$ & $\mathrm{NC}$ \\
\hline Asthma, bronchitis or emphysema & & 3.5 & 2.6 & NS & & -27.0 & $\mathrm{NC}$ \\
\hline Problems with leg or feet & & 4.9 & 4.0 & NS & & -17.3 & $\mathrm{NC}$ \\
\hline Stomach or bowel disorders & & 4.4 & 3.4 & NS & & -24.5 & $\mathrm{NC}$ \\
\hline Cardiovascular disease & & 7.3 & 5.8 & NS & & -20.0 & $\mathrm{NC}$ \\
\hline Mental disorders & & 14.7 & 12.2 & 9.7 & & -16.6 & -20.4 \\
\hline
\end{tabular}

${ }^{a}$ Deltas are only calculated on significant Bs; $N S$ not significant $(P \geq 0.05)$; $N C$ not calculated; relevant changes ( $\geq 10 \%$ change of significant Bs) are in bold type. Model 1: health status; model 2: model $1+$ work limitations; model 3: model $2+$ work characteristics; model 4: model $3+$ work adjustments

is hypothesized that the aim of realizing work adjustments is to reduce sick leave, this is a remarkable finding. Probably, the group with work adjustments is highly selective, because the reason for the realization of an adjustment at work may be a long period of sick leave.

Although differences were observed between the chronic illness groups, the hypothesis was confirmed for each chronic illness, i.e. that the contribution of poor perceived health status to the explanation of sick leave was dependent of work limitations, work characteristics, and work adjustments-was confirmed.

Our results are in agreement with previous studies that reported that a combination of health and factors at the workplace are associated with work-related outcomes 
$[6,9,23,24]$. However, to our knowledge, no study has yet quantified the contribution of work limitations, work characteristics and work adjustments to the association between perceived health and sick leave so far. Moreover, no study has demonstrated that this was the case for different groups of chronic illnesses.

\section{Methodological Considerations}

The major strength of this study is the dataset, which is large and representative for all employees in The Netherlands. However, a disadvantage of the database is that it is cross sectional, which implies that cause can not be distinguished from consequence. Lower health status may be the cause of sick leave, but episodes of sick leave, or work disability may lead to lower perceived health, and even mortality [17].

The information about sick leave, chronic illness and perceived health status was based on self-reported data, so recall and attribution bias may have occurred. Hence, a discrepancy between actual sick leave and self-reported sick leave cannot be ruled out. Recently, the self-report micro-data used in this study were linked, and compared to the national registration of absenteeism from work. This study showed that the validity of the self-reported data was at least as high as the registration data [25].

Data on all episodes of sick leave were analysed for this study; we did not restrict our analyses to sick leave due to a specific chronic illness, because sick leave is known to be multifactorial. Relying on respondents to report the cause of sick leave will lead to an under-estimation of sick leave related to their chronic illness.

The use of sick leave percentage in the current analyses implies that we can not distinguish between short-frequent and long term sick leave. This distinction may be of added value, because it has been found that the association between sick leave and low health status and mortality applied to long-term sick leave in particular [26-28].

\section{Implications for Research and Practice}

This cross-sectional study is the first step towards defining the role of work limitations, work characteristics, and work adjustments in the association between perceived health and sick leave. More longitudinal research is needed to determine the direction of the associations, and to distinguish between causes and consequences. However, some remarks can be made with regard to implications for practice.

Our results provide insight into the relationship between work factors and health, and their associations with sick leave. It is shown that, although differences exist between groups with different chronic illnesses, the common factor is that the relationship between health and sick leave is influenced by work factors. Intervening on the work factors of employees with a chronic illness may not only have a direct effect on sick leave and/or future health status, but may also have an impact on sick leave through health.

\section{Conclusion}

The main conclusions of this study are that the association between health and sick leave in employees with a chronic illness was partially explained by work limitations, work characteristics, and work adjustments. Similar patterns were observed for groups of employees with different chronic illnesses. We found no illness-specific relationship with work limitations, work characteristics and work adjustments. This supports a more general model of work disability, rather than an illness-specific model for the variables studied.

Open Access This article is distributed under the terms of the Creative Commons Attribution Noncommercial License which permits any noncommercial use, distribution, and reproduction in any medium, provided the original author(s) and source are credited.

\section{References}

1. Netherlands WHO Collaborating Centre for the Family of International Classifications. ICF: Dutch translation of the international classification of functioning, disability and health. Houten: Bohn Stafleu Van Loghum; 2007. (in Dutch).

2. Janssen F, Kunst AE. Cohort patterns in mortality trends among the elderly in seven European countries, 1950-99. Int J Epidemiol. 2005;34:1149-59.

3. Ben-Shlomo Y, Kuh D. A life course approach to chronic disease epidemiology: conceptual models, empirical challenges and interdisciplinary perspectives. Int J Epidemiol. 2002;31:285-93.

4. Omran AR. The epidemiologic transition. A theory of the epidemiology of population change. Milbank Mem Fund Q. 1971; 49:509-38.

5. Jehoel-Gijsbers G. Incapacity for work and reintegration. The Hague: The Netherlands Institute for Social Research; 2007.

6. Roskes K, Donders CG, van der Gulden JW. Health-related and work-related aspects associated with sick leave: a comparison of chronically ill and non-chronically ill workers. Int Arch Occup Environ Health. 2005;78:270-8.

7. Mitchell JM. The effect of chronic disease on work behavior over the life-cycle. South Econ J. 1990;56:928-42.

8. Bergh H, Baigi A, Mansson J, Mattsson B, Marklund B. Predictive factors for long-term sick leave and disability pension among frequent and normal attenders in primary health care over 5 years. Public Health. 2007;121:25-33.

9. Melloh M, Elfering A, Egli PC, Roeder C, Barz T, Rolli SC, et al. Identification of prognostic factors for chronicity in patients with low back pain: a review of screening instruments. Int Orthop. 2009;33:301-13.

10. Boot CR, van der Gulden JW, Orbon KH, Vercoulen JH, Akkermans R, van Weel C, et al. Asthma and chronic obstructive pulmonary disease: differences between workers with and without sick leave. Int Arch Occup Environ Health. 2004;77:357-62. 
11. Rytsala HJ, Melartin TK, Leskela US, Sokero TP, LestelaMielonen PS, Isometsa ET. Predictors of long-term work disability in major depressive disorder: a prospective study. Acta Psychiatr Scand. 2007;115:206-13.

12. Boot CR, Heijmans M, van der Gulden JW, Rijken M. The role of illness perceptions in labor participation of the chronically ill. Int Arch Occup Environ Health. 2008;82:13-20.

13. Baanders AN, Rijken PM, Peters L. Labour participation of the chronically ill: a profile sketch. Eur J Public Health. 2002; 12:124-30.

14. Mellner C, Krantz G, Lundberg U. Symptom reporting and selfrated health among women in mid-life: the role of work characteristics and family responsibilities. Int J Behav Med. 2006; 13:1-7.

15. De Raeve L, Jansen NW, Kant IJ. Health effects of transitions in work schedule, workhours and overtime in a prospective cohort study. Scand J Work Environ Health. 2007;33:105-13.

16. Grosch JW, Caruso CC, Rosa RR, Sauter SL. Long hours of work in the U.S.: associations with demographic and organizational characteristics, psychosocial working conditions, and health. Am J Ind Med. 2006;49:943-52.

17. Anema JR, van der Beek AJ. Medically certified sickness absence. Br Med J. 2008;337:a1174.

18. Van den Bossche SNJ, Koppes LLJ, Granzier JJM, De Vroome EMM, Smulders PGW. Netherlands working conditions survey 2007. Methods and general results. Hoofddorp: TNO Quality of Life; 2008.

19. Statistics Netherlands. Permanent investigation living situation health 2004. Heerlen: Statistics Netherlands; 2003. (in Dutch: POLS).

20. Lambeek LC, Van Mechelen M, Knol DL, Loisel P, Anema JR. Randomised controlled trial of integrated care to reduce disability from chronic low back pain in working and private life. Br Med J. 2010;340:c1035.
21. van Oostrom SH, Driessen MT, de Vet HC, Franche RL, Schonstein E, Loisel P, et al. Workplace interventions for preventing work disability. Cochrane database of systematic reviews; 2009. p. CD006955.

22. Franche RL, Severin CN, Hogg-Johnson S, Cote P, Vidmar M, Lee H. The impact of early workplace-based return-to-work strategies on work absence duration: a 6-month longitudinal study following an occupational musculoskeletal injury. J Occup Environ Med. 2007;49:960-74.

23. Burdorf A, Naaktgeboren B, Post W. Prognostic factors for musculoskeletal sickness absence and return to work among welders and metal workers. Occup Environ Med. 1998;55:490-5.

24. Dewa CS, Lin E. Chronic physical illness, psychiatric disorder and disability in the workplace. Soc Sci Med. 2000;51:41-50.

25. De Vroome EMM, Koppes LLJ, Smulders PGW, Van den Bossche SNJ. Measuring sickness absence through self-report and register data: differences between The Netherlands working conditions survey and the statistics Netherlands data on sick leave. TSG: Tijdschrift voor Gezondheidswetenschappen. 2010; 2:71-8. (in Dutch).

26. Gjesdal S, Ringdal PR, Haug K, Maeland JG, Vollset SE, Alexanderson K. Mortality after long-term sickness absence: prospective cohort study. Eur J Public Health. 2008;18:517-21.

27. Kivimaki M, Head J, Ferrie JE, Shipley MJ, Vahtera J, Marmot MG. Sickness absence as a global measure of health: evidence from mortality in the Whitehall II prospective cohort study. Br Med J. 2003;327:364.

28. Head J, Ferrie JE, Alexanderson K, Westerlund H, Vahtera J, Kivimaki M. Diagnosis-specific sickness absence as a predictor of mortality: the Whitehall II prospective cohort study. Br Med J. 2008;337:a1469. 